\section{Interferência do ácido ascórbico nas determinações de parâmetros bioquímicos séricos: estudos in vivo e in vitro}

\author{
Ascorbic acid interference on the measurement of serum biochemical parametersi in vivo and in vitro studies
}

Flávia Martinello ${ }^{1}$

Edson Luiz da Silva²

\section{unitermos resumo}

Ácido ascórbico

Interferência laboratorial

Analitos bioquímicos séricos

Reação de Trinder
Introdução: O ácido ascórbico, quando presente em amostras biológicas, pode interferir nos ensaios laboratoriais que utilizam reações de oxidorredução. Objetivos: Estabelecer o grau de interferência do ácido ascórbico nas determinações bioquímicas séricas em relação à dose de vitamina $C$, ingerida $\mathrm{e}$ ao tempo de coleta das amostras e comparar com o efeito interferente in vitro. Métodos: Voluntários saudáveis ( $n=18$ ) consumiram doses crescentes e sucessivas de 0,25 a $4 \mathrm{~g} /$ dia de vitamina $C$ durante uma semana cada dose. As determinações bioquímicas de ácido úrico, bilirrubina, colesterol total, glicose e triglicerídeos foram realizadas antes e 4, 12 e 24 horas após a última ingestão de cada dose. No estudo in vitro, concentrações crescentes de ácido ascórbico foram adicionadas ao soro humano e os analitos foram determinados até 24 horas após a adição. Resultados e Discussão: Os níveis séricos de ácido ascórbico aumentaram significativamente após a ingestão da vitamina $\mathrm{C}$, provocando inibição nas determinações de ácido úrico e bilirrubina total 4, 12 e 24 horas após a ingestão $(p<0,01)$. Em contrapartida, a ingestão de vitamina $C$ não interferiu nas determinações de glicose, colesterol e triglicerídeos. O ácido ascórbico inibiu in vitro as reações dos analitos estudados, diretamente proporcional à concentração de ácido ascórbico e inversamente proporcional à concentração dos analitos. Para o ácido úrico houve interferência analítica apenas, enquanto que para a bilirrubina a interferência foi analítica e, principalmente, metabólica. Conclusão: Para evitar resultados falso-negativos para ácido úrico e bilirrubina sugerimos a suspensão da ingestão de vitamina C 48 horas antes da coleta de sangue.
Background: Ascorbic acid, when present in biological samples, can produce a negative interference in several biochemical tests that use redox indicator systems. Objectives: We evaluated the ascorbic acid interference on serum biochemical tests in relation to the dose of vitamin $\mathrm{C}$ ingested and to the time of blood collection, and compared these results with in vitro interference. Methods: Healthy volunteers ( $n=18)$ consumed increasing and successive doses of vitamin C (0.25 to $4 \mathrm{~g} /$ day) for one week. Biochemical analytes were measured before and after each dose consumption. Serum samples were obtained 4, 12 and $24 \mathrm{~h}$ after vitamin $C$ ingestion. Ascorbic acid was added in vitro to the human serum and the biochemical analytes were assayed up to $24 \mathrm{~h}$ after addition. Results and discussion: Serum ascorbic acid increased significantly after vitamin $C$ ingestion,

inhibiting the assays for urate and total bilirubin up to $24 \mathrm{~h}$ after ingestion $(\mathrm{p}<0,01)$. In contrast, the ingested vitamin C did not interfere on the glucose, cholesterol, and triglycerides tests. In vitro ascorbic acid inhibited the reactions for all studied tests, proportional to the ascorbic acid amount and inversely proportional to the analyte concentrations. The urate test had in vitro interference only, whereas for bilirubin there were in vitro and, mainly, in vivo interference. Conclusion: To avoid false-negative results of serum urate and bilirubin we recommend the suspension of vitamin C intake at least 48 horas before blood collection.

\section{key words}

Ascorbic acid Laboratory interference Serum analytes Trinder's reaction
1. Farmacêutica bioquímica; mestre em farmácia, Análises Clínicas, pela Universidade Federal de Santa Catarina (UFSC). 2. Professor adjunto de bioquímica clínica do Departamento de Análises Clínicas, Centro de Ciências da Saúde da UFSC. Trabalho apresentado no $3^{\text {rd }}$ Congress of Pharmaceutical Sciences, Águas de Lindóia, SP, 2001, e no XXVIII Congresso Brasileiro de Análises Clínicas, Florianópolis, SC, 2001.

Tema da dissertação de mestrado intitulada Interferência do ácido ascórbico em determinações bioquímicas, 2001, apresentada no Programa de Pós-Graduação em Farmácia da UFSC. 


\section{Introdução}

A interferência de medicamentos em análises clínicas assume importante papel na rotina laboratorial por interferir nos ensaios e modificar o diagnóstico clinicolaboratorial. Recentemente, tem sido observado um aumento no consumo de suplementos vitamínicos, e o uso de altas doses de vitamina C (ácido ascórbico), particularmente, tornou-se um agravante para os analistas clínicos. $\mathrm{O}$ ácido ascórbico é facilmente absorvido e atinge níveis séricos relativamente elevados $(16,17)$. Quando presente em amostras biológicas, o ácido ascórbico, por ser um potente agente redutor, pode, em alguma etapa química, interagir com os constituintes dos reagentes analíticos utilizados na determinação do parâmetro bioquímico, causando um falso resultado na análise. Este fenômeno é conhecido como interferência in vitro ou analítica do ácido ascórbico. No entanto o ácido ascórbico pode, também, induzir alteração de um parâmetro bioquímico através de mecanismo fisiológico, chamado interferência in vivo. Ou, ainda, pode ocorrer interferência por ambos os mecanismos, simultaneamente. A diferenciação do mecanismo de interferência é de fundamental interesse para solucionar o problema. O ácido ascórbico é um conhecido interferente nas reações bioquímicas que envolvem os sistemas indicadores com oxidases e peroxidases, como a reação de Trinder. Esta reação é utilizada na quantificação de componentes séricos como glicose, colesterol, triglicerídeos e ácido úrico. Além de inibir a reação de Trinder, o ácido ascórbico pode, também, interferir nas reações para a determinação de bilirrubina, creatinina, fósforo, uréia e enzimas aminotransferases, lactato desidrogenase e fosfatase alcalina $(2,9,17,19,26,31)$.

Apesar de o efeito provocado pelo ácido ascórbico ser conhecido há muito tempo, poucos estudos avaliaram a interferência negativa em relação à dose de vitamina $\mathrm{C}$ ingerida e ao tempo de coleta da amostra (27). Além disso, existem recomendações dos fabricantes de reagentes no sentido de que, para evitar a interferência quando há suspeita da presença de ácido ascórbico, a análise deve ser repetida após 60-90min de permanência da amostra em temperatura ambiente. Entretanto sugerimos que este tempo pode ser dependente da concentração do ácido ascórbico na amostra. Assim, os objetivos desse estudo foram estabelecer o grau de interferência do ácido ascórbico nas determinações bioquímicas séricas em relação à dose de vitamina $\mathrm{C}$ ingerida e ao tempo de coleta das amostras e comparar esta interferência com o efeito in vitro após a adição de ácido ascórbico em amostras de soro. Verificamos, ainda, o tempo necessário para a auto-oxidação do ácido ascórbico e a conseqüente diminuição da interferência.

\section{Materiais e métodos}

\section{Materiais}

A vitamina $C$, comercializada na forma de comprimidos efervescentes ou em gotas (Redoxon ${ }^{\circledR}$, Roche), foi adquirida em farmácias. Os kits de reagentes foram gentilmente fornecidos por Labtest (Lagoa Santa, MG), Bioclin (Belo Horizonte, MG), Celm (Barueri, SP), BioSystems (Barcelona, Espanha) e Biodiagnóstica (Pinhais, PR). O ácido ascórbico e o ácido metafosfórico foram obtidos da Merck S.A. Os demais reagentes utilizados, ácido sulfúrico, 2,4dinitrofenil-hidrazina, tiouréia, sulfato de cobre e cloreto de sódio, foram de marcas nacionais.

\section{Protocolo experimental para estudo in vivo}

Foram selecionados indivíduos saudáveis $(n=18)$, nãofumantes e que estavam de acordo com o protocolo experimental aprovado pelo Comitê de Ética em Pesquisa com Seres Humanos da Universidade Federal de Santa Catarina (UFSC) (no 068/2000). Os voluntários consumiram diariamente, por via oral, doses crescentes e sucessivas de 250, 500, 1.000, 2.000 e $4.000 \mathrm{mg}$ de vitamina C. Cada dose foi ingerida de forma única após a última refeição do dia durante sete dias consecutivos e respeitando-se o intervalo de uma semana entre cada uma. As amostras de sangue foram coletadas na manhã do oitavo dia, 12 horas após a ingestão da respectiva dose de vitamina $\mathrm{C}$ e igual período de jejum. Após a coleta de sangue, os indivíduos ingeriram uma última dose de vitamina $C$, juntamente com um leve desjejum, e amostras subseqüentes foram coletadas após quatro e 24 horas. Durante a ingestão das doses inferiores a $2 \mathrm{~g}$ foi evitado o consumo de alimentos ricos em vitamina $\mathrm{C}$. Os soros foram isolados por centrifugação ( $750 \times$ g, $15 \mathrm{~min})$ e as determinações bioquímicas foram realizadas imediatamente utilizando-se os reagentes da Labtest Diagnóstica. Os resultados foram comparados com a média de três valores obtidos em diferentes semanas antes da suplementação com a vitamina C, após jejum de 4 e 12 horas (níveis basais de cada indivíduo).

\section{Protocolo experimental para estudo in vitro}

Quantidades crescentes de ácido ascórbico $(0,5$ a $40 \mathrm{mg} / \mathrm{dl}$, concentração final) foram adicionadas ao pool de soro. As determinações dos analitos bioquímicos foram realizadas na primeira hora após a adição do ácido ascórbico e após 2, 4, 6, 8 e 24 horas. Durante este perío- 
do de tempo as amostras foram armazenadas à temperatura ambiente e desprotegidas da luz. Ensaios adicionais foram realizados deixando-se as amostras a $4^{\circ} \mathrm{C}$.

\section{Determinações dos analitos bioquímicos}

As determinações dos analitos bioquímicos foram realizadas segundo as instruções dos fabricantes (Labtest, Bioclin, Celm, BioSystems e Biodiagnóstica), utilizando-se os seguintes métodos: reação de Trinder para glicose (glicose oxidase), colesterol total (colesterol oxidase), triglicerídeos (lipase e glicerol oxidase) e ácido úrico (uricase). O ácido úrico foi também determinado pelo método UV; o fósforo, pelo molibdênio; a uréia, pela uricase; a creatinina, pelo picrato alcalino com duas leituras em diferentes pHs (Jaffé); e a bilirrubina, por diazotação com o ácido sulfanílico.

\section{Determinação do ácido ascórbico sérico}

Os níveis de ácido ascórbico nas amostras de soro obtidas antes e após a suplementação oral com a vitamina $C$ foram determinados imediatamente após a coleta do sangue, utilizando-se o método espectrofotométrico da 2,4dinitrofenil-hidrazina (15).

\section{Estabilidade do ácido ascórbico em amostras de soro}

Após adição do ácido ascórbico em amostras de soro, 0 mesmo foi determinado pelo método da 2,4-dinitrofenil-hidrazina (15) e por cromatografia líquida de alta eficiência de fase reversa (HPLC-RF) (10), em diferentes períodos de tempo.

\section{Análise estatística}

As diferenças entre os valores obtidos antes e após a suplementação com a vitamina $C$ foram verificadas pela análise de variância (Anova) para medidas repetidas e teste complementar de Tukey, utilizando-se os três valores basais, ou teste $t$ pareado de Student considerando a média dos três valores basais. Foi realizada, também, a análise de regressão linear (correlação de Pearson) entre os valores dos analitos bioquímicos e os níveis de ácido ascórbico séricos e entre estes e a dose de vitamina $\mathrm{C}$ ingerida. Foi considerado um nível de significância de $p<0,05$.

\section{Resultados}

\section{Interferência do ácido ascórbico na determinação de parâmetros bioquímicos séricos in vivo}

Para verificar a interferência causada pelo ácido ascórbico nos ensaios laboratoriais, segundo a dose de vitamina $C$ ingerida e o tempo da coleta da amostra, foram realizadas coletas de sangue 4, 12 e 24 horas após o uso prolongado de diferentes doses de vitamina C. A determinação dos parâmetros bioquímicos em diferentes períodos de tempo teve como finalidade observar o grau de interferência do ácido ascórbico em relação aos seus níveis plasmáticos, considerando um pool corpóreo máximo obtido pela ingestão de vitamina $\mathrm{C}$ durante sete dias consecutivos.

A Figura 1 mostra os níveis de ácido ascórbico encontrados no soro de indivíduos saudáveis antes e após a ingestão das diferentes doses de vitamina C. A concentração de ácido ascórbico aumentou significativamente 4 horas após a ingestão de apenas $250 \mathrm{mg}$ de vitamina C em relação aos valores basais $(2,21$ vs. $1,13 \mathrm{mg} / \mathrm{dl}$, respectivamente, $p<0,05)$. Com a ingestão de doses maiores de vitamina $C$ ocorreu aumento crescente nos níveis de ácido ascórbico sérico $(r=0,91 ; p<0,01)$ (Figura 1B), atingindo o máximo de $3,28 \pm 0,5 \mathrm{mg} / \mathrm{dl}(0,21 \pm$ $0,03 \mathrm{mmol} / \mathrm{l}) \mathrm{com}$ a dose de $4 \mathrm{~g}$. A quantidade de ácido ascórbico presente no soro obtido 12 horas após a ingestão de 1,2 e $4 \mathrm{~g}$ de vitamina $C$ foi significativamente maior do que os níveis basais $(p<0,05)$, correlacionando-se, ainda, com a dose ingerida $(r=0,98 ; p<0,001)$. As amostras obtidas 24 horas após a ingestão de $4 \mathrm{~g}$ de vitamina $C$ apresentaram níveis de ácido ascórbico $60 \%$ maiores do que os basais $(p<0,05)$ (Figura 1A).

A Tabela 1 mostra os resultados dos analitos bioquímicos em amostras de sangue coletadas antes e quatro horas depois da ingestão de diferentes doses de vitamina C. As determinações realizadas antes da ingestão da vitamina $C$ foram utilizadas como controles (níveis basais), e a média delas foi considerada $100 \%$ para efetuar o cálculo do percentual de interferência negativa do ácido ascórbico. A variação biológica intra-individual encontrada para o ácido úrico foi de 5,1-6,5\%, e para a bilirrubina foi de $5-18,4 \%$.

Pode-se observar nas Tabelas 1 e 4 que os níveis séricos de ácido úrico sofreram interferência crescente à medida que os indivíduos consumiram doses maiores de vitamina C. O percentual de interferência nas determinações de ácido úrico diminuiu com o aumento do tempo de coleta após a última dose ingerida. A análise de regressão mostrou uma relação positiva entre os níveis séricos de ácido ascórbico e a percentagem de interferência negativa na reação de ácido úrico 4 horas após a ingestão de vitamina $C(r=0,75 ; p=0,05)$. Com a ingestão da menor dose de vitamina $C(0,25 \mathrm{~g} / \mathrm{d})$ houve diminuição de aproximadamente $18 \%$ nos valores de ácido úrico sérico $(p<0,01)$. A interferência aumentou para $29,44,58$ e $62 \%$ com a 


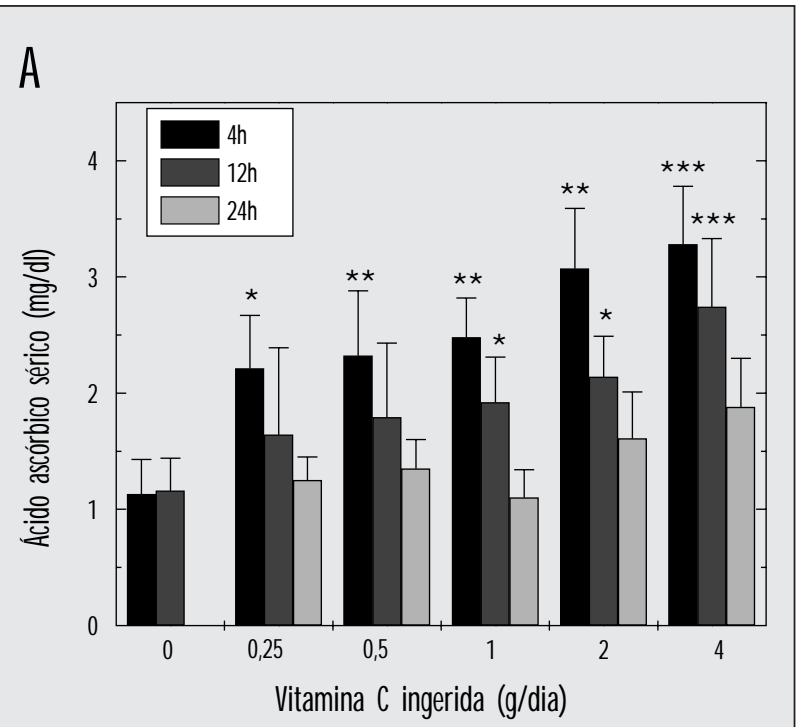

B

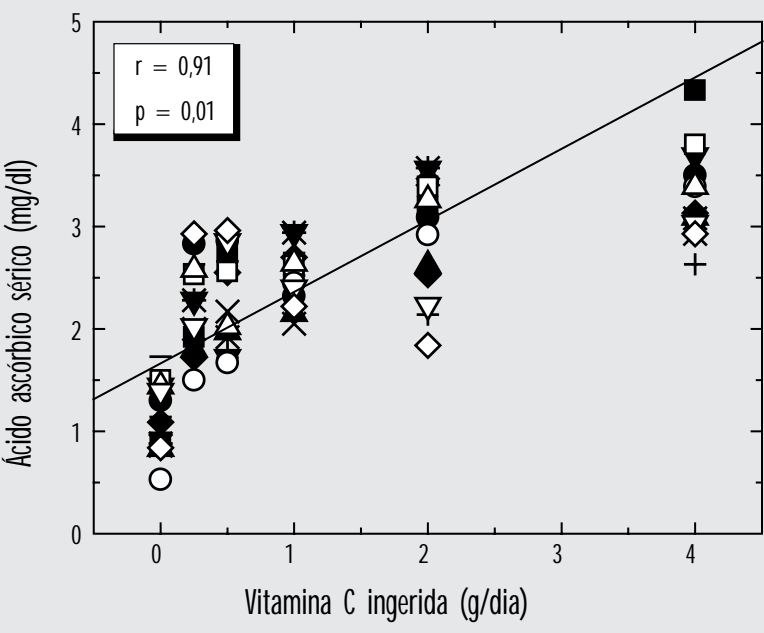

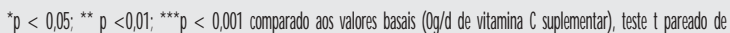

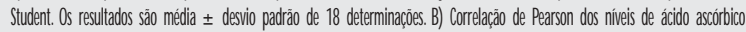
sérico, 4 horas após a ingestäo das várias doses de vitamina $C$.

Figura 1 - Níveis séricos de ácido ascórbico após a ingestão de vitamina C. A) Concentração sérica do ácido ascórbico determinada pelo método espectrofotométrico da 2,4-dinitrofenil-hidrazina

ingestão de 0,5, 1, 2 e 4g/d de vitamina $C$, respectivamente. A determinação de ácido úrico pelo método UV, o qual não forma peróxido de hidrogênio, não sofreu interferência significativa pela ingestão prolongada de $4 \mathrm{~g} / \mathrm{d}$ de vitamina C (Tabelas 1 e 2). Para o analito bilirrubina total (Tabelas 1 a 4 ) observou-se uma diminuição significativa de $34 \%, 27 \%, 28 \%$ e $27 \% 4$ horas após a ingestão de $0,5,1,2$ e $4 \mathrm{~g} / \mathrm{d}$ de vitamina $C$, respectivamente $(p<$ $0,05)$, não havendo correlação com a dose de vitamina $C$ ingerida $(r=0,56 ; p=0,25)$.
A Tabela 2 mostra os resultados dos parâmetros bioquímicos séricos obtidos de amostras coletadas 12 horas após a ingestão de vitamina C. Ainda ocorreram interferências significativas nas determinações de ácido úrico, porém em menor grau se comparadas com as interferências das amostras obtidas após 4 horas da ingestão de vitamina $C$. Níveis significativos de inibição na determinação de ácido úrico foram observados somente após a ingestão de doses $\geq$ $1 \mathrm{~g} / \mathrm{d}$ de vitamina C $(20-30 \%, p<0,001)$ (Tabelas 2 e 4). Em relação aos valores de bilirrubina, o nível de interferência foi semelhante ao de 4 horas, $20 \%$ a $28 \%(p<0,001$ e $p<0,05)$ (Tabelas 2 e 4). Os níveis de triglicerídeos diminuíram cerca de $34 \%(p<0,05) 12$ horas após a ingestão de $4 \mathrm{~g} / \mathrm{d}$ de vitamina C (Tabelas 2 e 4).

Os resultados obtidos 24 horas após a suplementação vitamínica estão mostrados na Tabela 3. O grau de interferência diminuiu sensivelmente em relação às amostras coletadas 4 e 12 horas após a ingestão. No entanto ainda foi possível observar uma inibição de $28 \%(p<0,01)$ na reação de ácido úrico com as amostras coletadas após a ingestão de $4 \mathrm{~g} / \mathrm{d}$ de vitamina C (Tabela 4).

Resultados semelhantes, em relação aos níveis de significância, foram também obtidos pela análise de variância (Anova) e pelo teste complementar de Tukey, utilizandose os três valores basais como controles.

\section{Interferência do ácido ascórbico na determinação de parâmetros bioquímicos séricos in vitro}

Os experimentos in vitro foram realizados com o objetivo de comparar os níveis de interferência com aqueles observados in vivo e verificar o tempo necessário para a oxidação do ácido ascórbico e a conseqüente diminuição da interferência. O ácido ascórbico foi adicionado ao soro em concentrações semelhantes àquelas encontradas no soro de voluntários saudáveis após a suplementação oral com vitamina $C$. No entanto níveis séricos superiores aos valores observados podem ser encontrados após terapias com megadoses de vitamina C injetável. Assim, ácido ascórbico foi também adicionado ao soro para se obter as concentrações de 10 e 40mg/dl (concentração final).

As reações para creatinina, uréia e fósforo não sofreram interferência, inclusive com a maior concentração de ácido ascórbico estudada (resultados não-mostrados). Os resultados das determinações bioquímicas séricas pelo método de Trinder e da bilirrubina realizadas em pool de soro antes e após a adição das várias concentrações de ácido ascórbico estão demonstrados na Figura 2 e na Tabela 5. O efeito interferente do ácido ascórbico foi semelhante para os dife- 


\section{Parâmetros bioquímicos séricos ( $\mathrm{mg} / \mathrm{dl}$ ) determinados antes e 4 horas após a ingestão de}

Tabela 1 vitamina C

\section{Vitamina C suplementar ( $g /$ dia)}

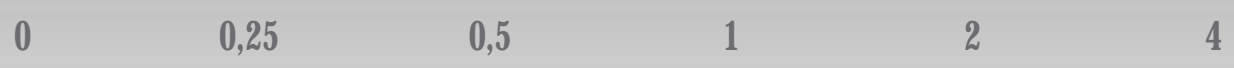

$\begin{array}{lcccccc}\begin{array}{l}\text { Ácido ascórbico } \\ \text { (mg/ dl) }\end{array} & 1,13 \pm 0,3 & 2,21 \pm 0,46^{*} & 2,32 \pm 0,56^{*} & 2,48 \pm 0,34^{* *} & 3,07 \pm 0,52^{* * *} & 3,28 \pm 0,5^{* * *} \\ \begin{array}{l}\text { Ácido úrico } \\ \text { (Trinder) }\end{array} & 4,5 \pm 1,6 & 3,6 \pm 1,4^{* *} & 3,1 \pm 1,1^{* * *} & 2,5 \pm 0,8^{* *} & 1,9 \pm 0,9 * * * & 1,7 \pm 0,9 * * \\ \text { Ácido úrico UV } & 5,8 \pm 2 & \mathrm{ND} & \mathrm{ND} & \mathrm{ND} & \mathrm{ND} & 5 \pm 2,6 \\ \text { Bilirrubina total } & 0,67 \pm 0,19 & 0,68 \pm 0,18 & 0,43 \pm 0,15^{* *} & 0,48 \pm 0,13^{*} & 0,48 \pm 0,22^{*} & 0,49 \pm 0,12^{* *} \\ \text { Colesterol total } & 155 \pm 16,3 & 164 \pm 36,2 & 163 \pm 19,3 & 168 \pm 31,5 & 162 \pm 35,7 & 170 \pm 26,6 \\ \text { Glicose } & 86 \pm 5,2 & 83 \pm 10,3 & 92 \pm 10,2 & 88 \pm 11,2 & 84 \pm 6,8 & 93 \pm 5,9 \\ \text { Triglicérides } & 92 \pm 34,5 & 98 \pm 35,1 & 82 \pm 9,6 & 101 \pm 37,5 & 68 \pm 36,8 & 71 \pm 27,7\end{array}$

Voluntários saudáveis $(n=18)$ ingeriram doses crescentes de vitamina $C$, sendo que cada dose foi consumida por uma semana, e as determinações dos analitos foram realizadas 4 horas após a ingestão da última dose de vitamina $C$.

${ }^{*} p<0,05 ;{ }^{* *} p<0,01 ;{ }^{* \star *} p<0,001$, teste $t$ pareado de Student comparado ao respectivo controle ( 0 vit. C). ND = não-determinado.

Tabela 2

\section{vitamina C}

Parâmetros bioquímicos séricos ( $\mathrm{mg} / \mathrm{dl})$ determinados antes e 12 horas após a ingestão de

\begin{tabular}{|c|c|c|c|c|c|c|}
\hline & & & Vitamina C sup & ementar ( g/dia) & & \\
\hline & 0 & 0,25 & 0,5 & 1 & 2 & 4 \\
\hline $\begin{array}{l}\text { Ácido ascórbico } \\
\text { (mg/ dl) }\end{array}$ & $1,16 \pm 0,28$ & $1,64 \pm 0,75$ & $1,79 \pm 0,64$ & $1,92 \pm 0,39 *$ & $2,14 \pm 0,35 * * *$ & $2,74 \pm 0,59 * * *$ \\
\hline $\begin{array}{l}\text { Ácido úrico } \\
\text { (Trinder) }\end{array}$ & $4,1 \pm 1,53$ & $4,3 \pm 1,22$ & $4,1 \pm 1,32$ & $3,3 \pm 1,36 * * *$ & $3,0 \pm 1,36 * * *$ & $2,8 \pm 1,05 * * *$ \\
\hline Ácido úrico UV & $4,7 \pm 1,7$ & ND & ND & ND & ND & $4,5 \pm 1,6$ \\
\hline Bilirrubina total & $0,72 \pm 0,2$ & $0,71 \pm 0,11$ & $0,55 \pm 0,28 * * *$ & $0,55 \pm 0,15^{* * *}$ & $0,55 \pm 0,2^{*}$ & $0,52 \pm 0,18^{*}$ \\
\hline Colesterol total & $158 \pm 16,8$ & $165 \pm 32,1$ & $168 \pm 25,1$ & $169 \pm 21,3$ & $162 \pm 31,8$ & $155 \pm 20,2$ \\
\hline Glicose & $84 \pm 6,2$ & $93 \pm 11,8$ & $86 \pm 15,1$ & $78 \pm 12,9$ & $81 \pm 8,6$ & $88 \pm 9,8$ \\
\hline Triglicérides & $82 \pm 39,1$ & $80 \pm 35$ & $88 \pm 29,5$ & $77 \pm 22,8$ & $62 \pm 20,3$ & $54 \pm 19,7^{*}$ \\
\hline
\end{tabular}

Voluntários saudáveis $(n=18)$ ingeriram doses crescentes de vitamina C, sendo que cada dose foi consumida por uma semana, e as determinações dos analitos foram realizadas 12 horas após a ingestão da última dose de vitamina $C$.

${ }^{*} p<0,05 ;{ }^{* *} p<0,01 ;{ }^{* * *} p<0,001$, teste $t$ pareado de Student comparado ao respectivo controle (0 vit. C). ND = não-determinado.

Tabela 3

\section{Parâmetros bioquímicos séricos ( $\mathrm{mg} / \mathrm{dll})$ determinados antes e 24 horas após a ingestão de} vitamina C

\section{Vitamina C suplementar ( $g /$ dia)}

0

0,5

1

2

4

Ácido ascórbico (mg/ dl) $1,16 \pm 0,28$

Ácido úrico (Trinder) $\quad 3,8 \pm 1,37$

$\begin{array}{ll}1,35 \pm 0,25 & 1,1 \pm 0,24 \\ 3,6 \pm 1,59 & 3,4 \pm 1,32 \\ 0,63 \pm 0,15 & 0,72 \pm 0,16\end{array}$

$1,61 \pm 0,4$

$1,88 \pm 0,42^{*}$

Bilirrubina

$0,65 \pm 0,18$

$0,63 \pm 0,15$

$3,25 \pm 1,35$

$2,72 \pm 1,3 * *$

$0,69 \pm 0,23$

$0,58 \pm 0,24$

Voluntários saudáveis $(n=18)$ ingeriram doses crescentes de vitamina $C$, sendo que cada dose foi consumida por uma semana, e as determinações dos analitos foram realizadas 24 horas após a ingestão da última dose de vitamina $C$.

${ }^{*} p<0,05 ;{ }^{* *} p<0,01$, teste $t$ pareado de Student comparado ao respectivo controle (0 vit. C). 
Tabela 4 (\% de inibição \pm DP $)$

\begin{tabular}{|c|c|c|c|c|c|}
\hline & & Vitamina C su & entar ( g/ dia) & & \\
\hline & 0 & 0,5 & 1 & 2 & 4 \\
\hline 4 horas & & & & & \\
\hline $\begin{array}{l}\text { Ácido úrico } \\
\text { Bilirrubina }\end{array}$ & $\begin{array}{c}17,8 \pm 7,1^{* *} \\
0\end{array}$ & $\begin{array}{c}28,9 \pm 10,7 * * * \\
34,3 \pm 13,2 * *\end{array}$ & $\begin{array}{c}44,4 \pm 14,2^{* *} \\
26,9 \pm 10,3^{*}\end{array}$ & $\begin{array}{c}57,8 \pm 27,2^{* * *} \\
28,3 \pm 12,6 *\end{array}$ & $\begin{array}{c}62,2 \pm 30^{* *} \\
27,2 \pm 14,7 * *\end{array}$ \\
\hline 12 horas & & & & & \\
\hline Ácido úrico & 0 & 0 & $19,5 \pm 7,6 * * *$ & $26,8 \pm 12,1 * * *$ & $31,7 \pm 11,8^{* * *}$ \\
\hline Bilirrubina & ND & $20,8 \pm 9,4 * * *$ & $22,2 \pm 5,7^{* * *}$ & $23,6 \pm 8,3^{*}$ & $27,8 \pm 9,4^{*}$ \\
\hline Triglicérides & 0 & 0 & $7,45 \pm 2,6$ & $27,8 \pm 8,9$ & $34,3 \pm 12,2^{*}$ \\
\hline 24 horas & & & & & \\
\hline Ácido úrico & ND & ND & $9,9 \pm 3,8$ & $13,1 \pm 5,2$ & $28,4 \pm 13,4^{* *}$ \\
\hline Bilirrubina & ND & ND & 0 & 0 & $12,1 \pm 4,8$ \\
\hline
\end{tabular}

Os valores foram obtidos pelo cálculo do percentual de interferência dos valores expressos nas Tabelas 1,2 e 3 , considerando controle a média de três valores basais antes da ingestão da vitamina $C$.

${ }^{*} p<0,05 ;{ }^{* *} p<0,01 ;{ }^{* * *} p<0,001$, em comparação com o controle (teste $t$ pareado de Student). ND = não-determinado.

Interferência negativa in vitro do ácido ascórbico (\% do controle) na determinação de Tabela 5 colesterol total, glicose, triglicérides e bilirrubina

5

\section{Ácido ascórbico (mg/dll)*}

10
40

\section{Tempo (h) Colesterol}

0
2
4
6
8
2
0
2
4
6
8
2
0
2
4
6
8
24

2

4

6

8

24

Glicose

0
2
4
6
8
24

0
2
4
6
8
24

$$
\begin{gathered}
15,8 \pm 5,2 \\
13,5 \pm 3,7 \\
10,2 \pm 1,8 \\
6,5 \pm 2,7 \\
2,8 \pm 1,1 \\
\text { ND }
\end{gathered}
$$

$$
\begin{array}{r}
11,5 \pm 2,7 \\
8,5 \pm 1,1 \\
8,1 \pm 1,8 \\
7,9 \pm 1,5 \\
7,8 \pm 1,2 \\
2,8 \pm 0,4
\end{array}
$$

Triglicérides

2

$$
\begin{aligned}
& 33,6 \pm 5,2 \\
& 31,0 \pm 6,3 \\
& 30,7 \pm 2,9 \\
& 26,1 \pm 3,1 \\
& 15,1 \pm 2,1 \\
& 10,6 \pm 1,4
\end{aligned}
$$

$9,4 \pm 1,7$
$N D$
$N D$
$N D$
$N D$
$N D$

$21,1 \pm 4,6$

$18,7 \pm 3,6$

$17,6 \pm 3,1$

$10,8 \pm 2,2$

$9,8 \pm 2,9$

$8,5 \pm 1,7$

$18,6 \pm 1,3$

$16,7 \pm 1,9$

$15,2 \pm 2,5$

$15,1 \pm 1,8$

$14,7 \pm 1,4$

$6,0 \pm 1,2$

$60,6 \pm 3,3$

$57,1 \pm 3,2$

$56,3 \pm 2,5$

$51,5 \pm 2,1$

$50,4 \pm 1,8$

$30,1 \pm 2,2$

$$
\begin{gathered}
11,5 \pm 2,5 \\
8,9 \pm 1,8 \\
7,6 \pm 0,7 \\
6,3 \pm 1,5 \\
3,1 \pm 0,9
\end{gathered}
$$

ND
$69,9 \pm 7,2$

$60,8 \pm 5,5$

$56,8 \pm 6,8$

$51,1 \pm 7,5$

$44,5 \pm 4,1$

$34,7 \pm 2,8$

$54,5 \pm 4,4$

$52,7 \pm 5,2$

$51,9 \pm 6,4$

$47,5 \pm 5,5$

$41,7 \pm 4,2$

$28,9 \pm 1,9$

$97,7 \pm 1,2$

$97,5 \pm 4,1$

$96,3 \pm 5,2$

$95,2 \pm 4,6$

$94,0 \pm 3,1$

$93,4 \pm 2,1$

$56,9 \pm 3,1$

$54,8 \pm 2,5$

$53,2 \pm 1,5$

$52,8 \pm 1,8$

$51,6 \pm 4,1$

$40,3 \pm 2,1$

Os ensaios foram realizados em diferentes períodos de tempo, utilizando-se os reagentes de Labtest, Bioclin, Biodiagnóstica, Biosystems e Celm antes (controle) e após a adição do ácido ascórbico ao soro. Os resultados das diferentes marcas de reagentes foram combinados e estão expressos como média \pm desvio padrão de dois ou três ensaios realizados com cada variável em diferentes pools de soro. ND = não-determinado. *Concentração final. 
rentes reagentes das várias marcas comerciais estudadas. Assim os resultados estão expressos como média \pm desvio padrão de duas ou três determinações para cada variável realizada com os diferentes reagentes.

Os resultados mostraram que o ácido ascórbico provocou inibição das reações de oxidase/peroxidase de todos os analitos estudados. O grau de inibição foi diretamente proporcional à concentração de ácido ascórbico adicionado às amostras. A reação para a determinação de ácido úrico foi a que mais sofreu interferência pelo ácido ascórbico, seguida pelos ensaios para triglicerídeos, colesterol total e glicose (Figura 2A). Com a concentração de $5 \mathrm{mg} / \mathrm{dl}$ de ácido ascórbico na amostra, a reação para o ácido úrico foi inibida em cerca de $84 \%$ contra $34 \%$, 12\% e 11\% de interferência nas determinações de triglicerídeos, colesterol total e glicose, respectivamente (Figura 2A). Esta diferença de sensibilidade ao ácido ascórbico foi decorrente da quantidade do analito presente no sistema de reação, pois, ao se normalizarem os resultados em termos molares analito:ácido ascórbico, observou-se que todos os ensaios apresentaram uma estequiometria de 1:1 (Figura 2B). Por exemplo, a relação molar analito:ácido ascórbico de 0,5:1 resultou em aproximadamente $50 \%$ de interferência negativa para todos os ensaios. Assim, a interferência negativa foi proporcional à quantidade de ácido ascórbico e inversamente proporcional à concentração do analito presente no sistema de reação. Para colesterol, glicose e triglicerídeos interferências significativas ocorreram apenas com as mais altas concentrações de ácido ascórbico estudadas, 10 e 40mg/dl (Tabela 5).

O ensaio para a determinação da bilirrubina total não sofreu interferência significativa in vitro na presença de ácido ascórbico inferior a $10 \mathrm{mg} / \mathrm{dl}$. Apenas quando $40 \mathrm{mg} / \mathrm{dl}$ de ácido ascórbico foram adicionados ao soro ocorreu em média $57 \%$ de interferência negativa (Tabela 5). É interessante notar, porém, que os resultados dos estudos in vivo, após a ingestão de vitamina C, demonstraram haver interferência negativa no ensaio para bilirrubina com concentrações menores de ácido ascórbico (Tabelas 1 a 4). Assim, para compararmos ambos os resultados, in vivo e in vitro, os dados foram normalizados em termos molares de ácido ascórbico:bilirrubina e verificamos que a interferência in vivo foi realmente maior que aquela in vitro (Figura 3A). Para uma relação molar ácido ascórbico: bilirrubina de 3,4 a interferência na determinação de bilirrubina in vitro foi de aproximadamente $10 \%$ contra cerca de $35 \%$ in vivo. Considerando também a possibili- dade de interferência do ácido ascórbico no metabolismo do ácido úrico, análise semelhante foi realizada com os resultados dos níveis de interferência in vivo e in vitro. A Figura 3B mostra que o grau de interferência do ácido ascórbico foi semelhante nas duas situações, indicando haver apenas interferência analítica.

Muitos fabricantes de reagentes preconizam em seus manuais de instrução que, havendo suspeita da presença de ácido ascórbico, os ensaios laboratoriais devem ser repetidos 60-90min após repouso da amostra, para evitar o efeito interferente do ácido ascórbico. As determinações

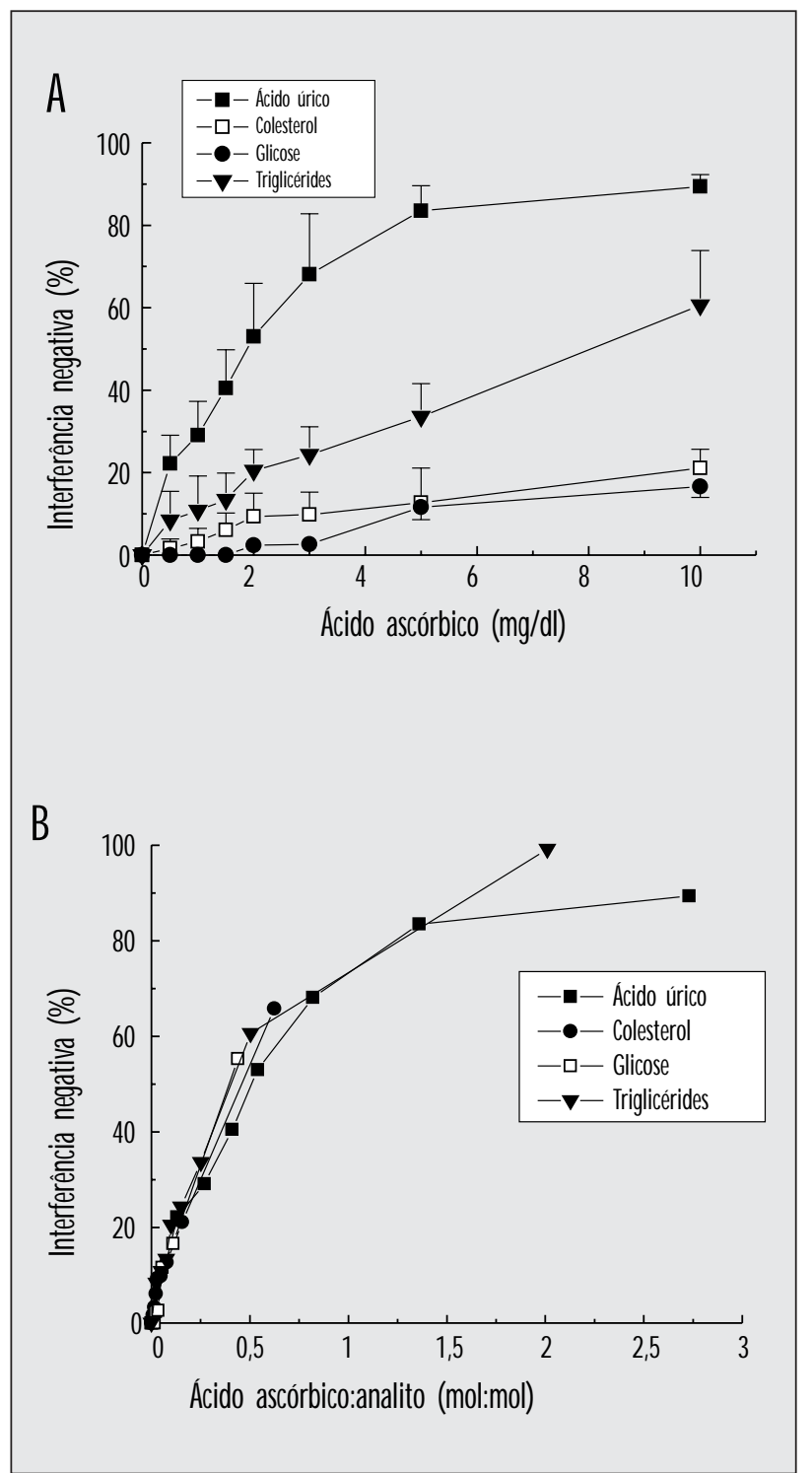

Figura 2 - Interferência negativa do ácido ascórbico in vitro na determinação de ácido úrico, colesterol, glicose e triglicérides pelo sistema oxidase/peroxidase. A) Ácido ascórbico foi adicionado ao soro (concentração final), e as determinações dos analitos foram realizadas antes (controle) e 1-2 horas após a adição. B) Os resultados foram normalizados em termos molares de ácido ascórbico:analitos. Os resultados são média \pm desvio padrão dos ensaios realizados com os reagentes de Labtest, Bioclin, Biodiagnóstica, Biosystems e Celm (dois ou três ensaios para cada analito) 


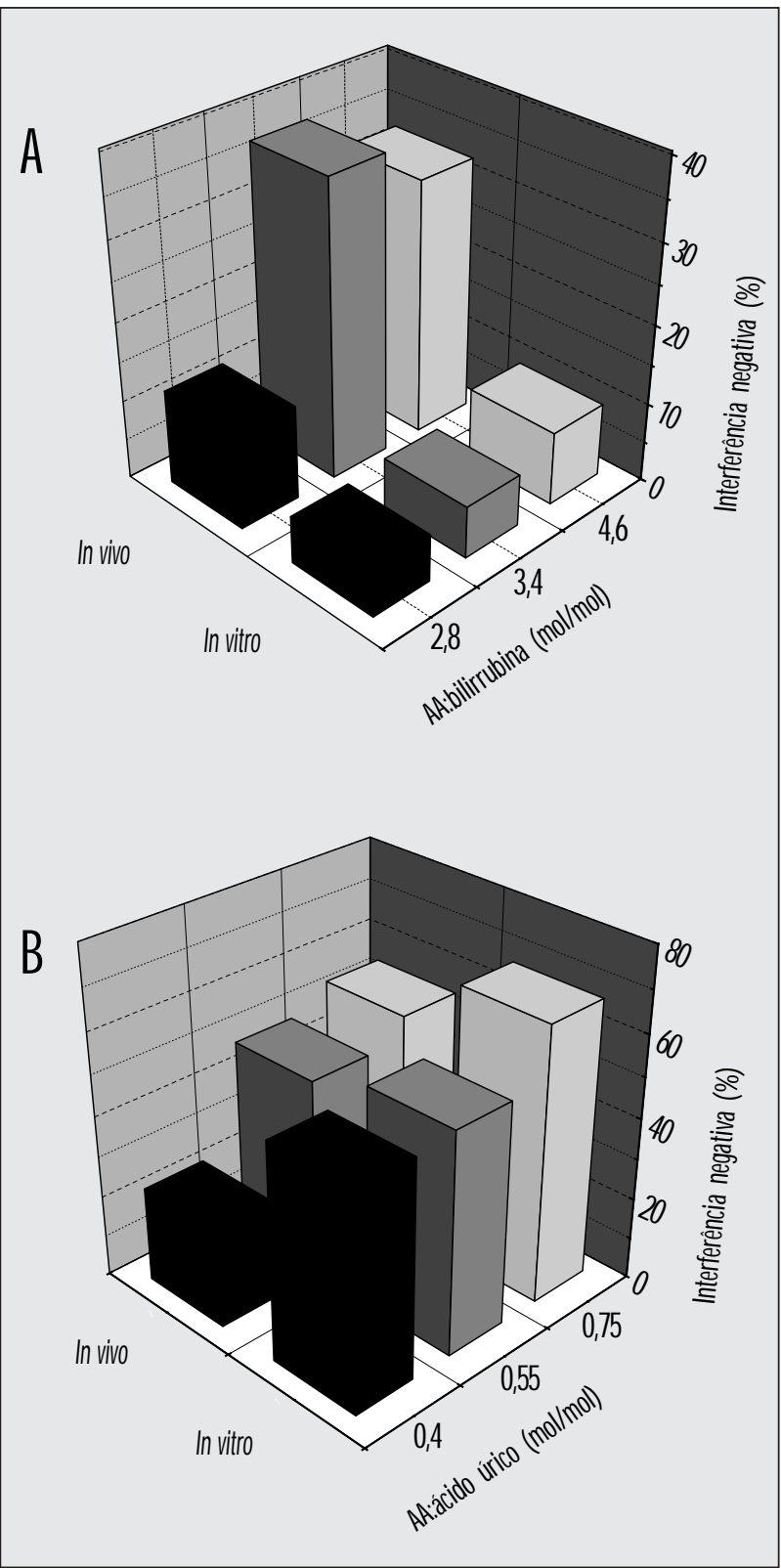

Figura 3 - Interferência negativa do ácido ascórbico na determinação de (A) bilirrubina total e (B) ácido úrico. Para efeito de comparação, os resultados obtidos 4 e 12 horas após a ingestão de vitamina C (Tabelas 1 e 2) e após a adição de ácido ascórbico ao pool de soro (Tabela 5 e Figura 2) foram normalizados em termos molares de ácido ascórbico:analito

realizadas após a adição do ácido ascórbico demonstraram que, dependendo da concentração deste na amostra, ocorreram ainda importantes graus de interferência após 4, 6, 8 e 24 horas (Tabela 5 e Figura 4). Para a reação do ácido úrico na presença de $5 \mathrm{mg} / \mathrm{dl}$ de ácido ascórbico ocorreram ainda, em média, 38\% de interferência negativa após 24 horas (Figura 4). Com 10 e 40mg/ dl de ácido ascórbico a interferência na determinação de ácido úrico permaneceu praticamente inalterada e próxima de 100\%. Mesmo com pequenas concentrações de ácido ascórbico adicionadas (concentração final de $1 \mathrm{mg} / \mathrm{dl}$ ) a in-

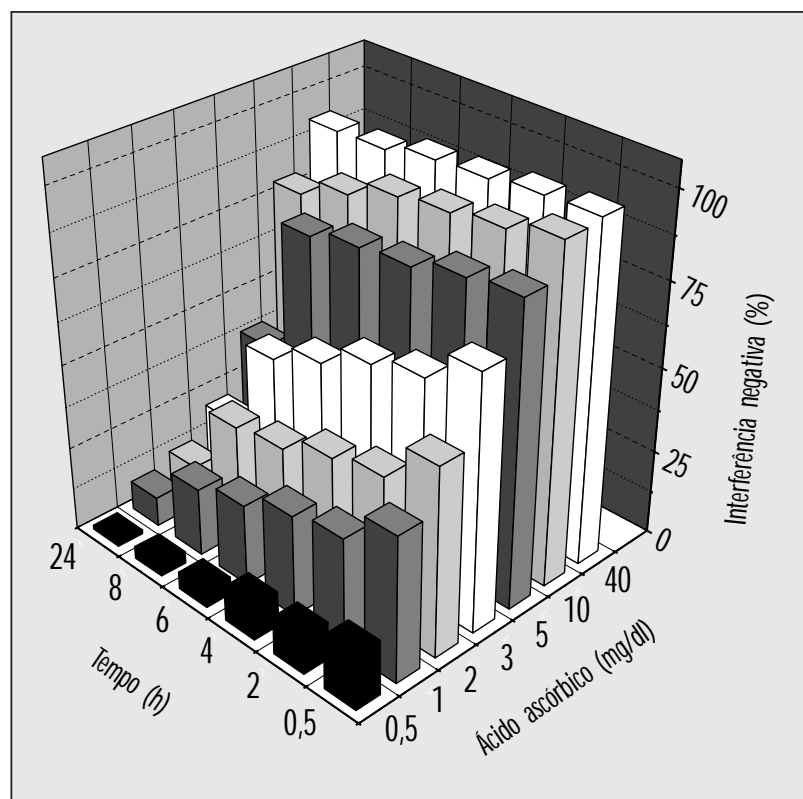

Figura 4 - Interferência negativa do ácido ascórbico na determinação de ácido úrico. Ácido ascórbico (concentração final) foi adicionado ao pool de soro e as determinações foram realizadas após diferentes períodos de tempo. As amostras permaneceram à temperatura ambiente. Os resultados são médias de duas ou três determinações para cada variável realizada com os diferentes reagentes estudados, os quais utilizam o sistema oxidase/peroxidase

terferência persistiu até 24 horas (Figura 4). Para os demais analitos a interferência permaneceu até 24 horas somente com $40 \mathrm{mg} / \mathrm{dl}$ de ácido ascórbico no soro (Tabela 5). Níveis de interferência maiores e por um longo período de tempo foram observados quando as amostras permaneceram a $4^{\circ} \mathrm{C}$, como, por exemplo, $42 \%$ de interferência negativa para a reação do ácido úrico 24 horas após a adição de $5 \mathrm{mg} / \mathrm{dl}$ de ácido ascórbico. Após a adição de $40 \mathrm{mg} / \mathrm{dl}$, a inibição da reação foi total durante o período estudado de 72 horas. Para os demais analitos, $5 \mathrm{mg} / \mathrm{dl}$ de ácido ascórbico provocaram interferência negativa por até 6 horas a $4^{\circ} \mathrm{C}$.

Com base nesses resultados foi verificada, então, a estabilidade do ácido ascórbico nas amostras de soro. Determinamos os níveis de ácido ascórbico após diferentes períodos de tempo, por cromatografia líquida de alta eficiência (HPLC) e pelo método espectrofotométrico da 2,4-dinitrofenil-hidrazina (DNPH), o qual mede o conjunto dos ácidos ascórbico, deidroascórbico e dicetogulônico. A Figura 5 mostra a quantidade residual de ácido ascórbico após a sua auto-oxidação em amostras de soro contendo inicialmente de 0,5 a $40 \mathrm{mg} / \mathrm{dl}$ de ácido ascórbico. A meia-vida do ácido ascórbico nas amostras de soro foi de aproximadamente 15 horas quando avaliada por HPLC e 48 horas pelo método colorimétrico da 2,4-DNPH (Figura 5). 


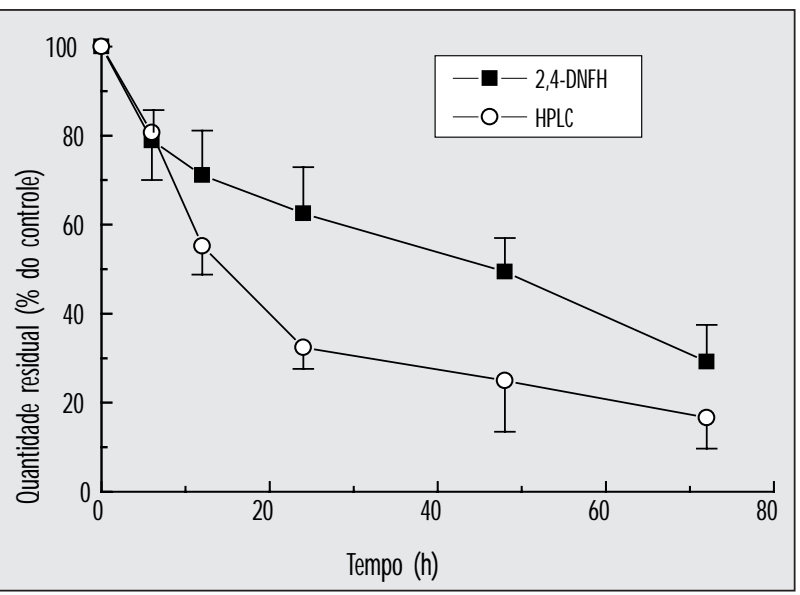

Figura 5 - Estabilidade do ácido ascórbico em soro. Quantidades crescentes de ácido ascórbico (concentração final: 0,5 a 40mg/dl) foram adicionadas em pool de soro e as determinações foram realizadas pelo método espectrofotométrico da 2,4dinitrofenil-hidrazina (2,4-DNFH) e por HPLC-RF. Os níveis de ácido ascórbico quantificados na primeira hora após a adição ao soro foram considerados controles. Os resultados são média \pm desvio padrão de duas determinações com diferentes pools de soro para cada concentração

A existência de produtos de oxidação do ácido ascórbico com poder redutor (13) levou-nos a investigar o efeito do ácido deidroascórbico como primeiro produto de oxidação do ácido ascórbido. Concentrações crescentes de ácido deidroascórbico, semelhantes àquelas de ácido ascórbico, foram adicionadas ao soro e as determinações dos vários analitos bioquímicos foram realizadas. Os resultados demonstraram que o ácido deidroascórbico não interferiu nas reações de Trinder (dados não-mostrados).

\section{Discussão}

O uso de tratamentos alternativos baseados na ingestão de vitaminas tem aumentado significativamente o consumo de vitamina $C$ pela população em geral. A vitamina $C$ tem sido indicada para pacientes com câncer (4-6) e também com a finalidade de prevenção de várias outras doenças (7).

Os resultados desse estudo demonstraram que a vitamina $\mathrm{C}$, em doses normalmente consumidas de forma prolongada (uma semana) por pessoas saudáveis, interferiu significativamente em alguns ensaios laboratoriais, dependendo da dose ingerida e do tempo em que as amostras de sangue foram coletadas após o consumo da vitamina.

A concentração de ácido ascórbico sérico antes da suplementação foi de 1 a 1,2mg/dl (Figura 1A), portanto dentro dos valores de referência, que são de 0,3 a $2 \mathrm{mg} / \mathrm{dl}$ (15). Os níveis de ácido ascórbico aumentaram cerca de duas vezes $(p<0,05) 4$ horas após a ingestão de pequena dose de vitamina C (250mg) (Figura 1A). Este aumento do ácido ascórbico foi suficiente para provocar uma inibição de $17,8 \%(p<0,01)$ na reação para a determinação de ácido úrico sérico com base no sistema uricase/peroxidase (Tabelas 1 a 4). Podmore et al. (22) demonstraram um aumento de $60 \%$ nos níveis de ácido ascórbico sérico após a ingestão de $500 \mathrm{mg} / \mathrm{d}$ de vitamina $C$. A concentração sérica de ácido ascórbico aumentou significativamente com a ingestão de doses maiores de vitamina $C(r=0,91$; $p<0,01$ ) (Figura 1B), causando uma interferência negativa máxima de $62 \%$ na determinação de ácido úrico 4 horas após a ingestão de $4 \mathrm{~g} / \mathrm{d}$ de vitamina C (Tabela 4).

O tempo necessário para a eliminação plasmática do excesso de ácido ascórbico e o retorno aos valores basais, após a interrupção da suplementação vitamínica, foi dependente da dose ingerida (Figura 1A). Assim, as doses $\leq 0,5 \mathrm{~g} / \mathrm{d}$ foram praticamente eliminadas nas primeiras 12 horas após a ingestão, enquanto que foram necessárias 24 horas para a completa eliminação do excesso obtido com as doses de 1 e $2 \mathrm{~g} / \mathrm{d}$ e pelo menos 48 horas para a dose de $4 \mathrm{~g} / \mathrm{d}$ de vitamina $\mathrm{C}$ (Figura $1 \mathrm{~A}$ ). Conseqüentemente, o grau de inibição observado nos ensaios de ácido úrico foi progressivamente menor nas amostras coletadas 12 e 24 horas após a ingestão de vitamina C, em comparação com as amostras de 4 horas (Tabela 4). Merece destaque o fato de a ingestão de uma dose moderada de vitamina C $(1 \mathrm{~g} / \mathrm{d})$ ter provocado interferência significativa na determinação de ácido úrico em amostras de sangue coletadas 12 horas após a ingestão e no caso de $4 \mathrm{~g} / \mathrm{d}$, inclusive, 24 horas após (Tabelas 2 a 4).

As interferências observadas nas reações para a determinação da bilirrubina total (diazotação) foram significativas nas amostras coletadas 4 e 12 horas após a ingestão de doses $\geq 0,5 \mathrm{~g} / \mathrm{d}$ de vitamina $C$. No entanto o grau de inibição não apresentou correlação com os níveis séricos de ácido ascórbico $(r=0,56 ; p>0,05)$. Ou seja, os percentuais de interferência foram semelhantes nas amostras coletadas 4 e 12 horas após a ingestão de 0,5, 1, 2 ou $4 \mathrm{~g} / \mathrm{d}$ de vitamina C. Os níveis de triglicerídeos diminuíram em média $22,7 \% 4$ horas após a ingestão de $4 \mathrm{~g}$ de vitamina $C$, porém esta variação não foi estatisticamente significativa em nível de $5 \%$ (Tabela 1) e também encontra-se abaixo dos valores de variação biológica preconizados por Marcovina et al. (14). No entanto, após jejum de 12 horas, houve uma inibição significativa de $34 \%$ $(p<0,05)$ após a ingestão de $4 \mathrm{~g}$ de vitamina $\mathrm{C}$, provavel- 
mente devido à menor quantidade de triglicerídeos na amostra (Tabelas 2 e 4).

É interessante notar que, mesmo com a maior dose de vitamina $C$ estudada $(4 \mathrm{~g} / \mathrm{d})$, não ocorreu interferência significativa nas reações para a determinação de glicose e colesterol total (Tabelas 1 e 2). Utilizando concentrações mais elevadas de ácido ascórbico em experimentos in vitro, sem considerar, portanto, a meia-vida biológica do ácido ascórbico, outros pesquisadores relataram inibição significativa para a maioria dos ensaios que utilizam reações de oxidorredução $(9,19,20,23$, 34). Naturalmente, concentrações elevadas de ácido ascórbico podem ser encontradas no soro de pacientes que estão recebendo tratamento com megadoses de vitamina C. Badrick e Campbell (2) encontraram até $30 \mathrm{mmol} / \mathrm{l}(528 \mathrm{mg} / \mathrm{dl})$ de ácido ascórbico no plasma após a infusão de $30 \mathrm{~g}$ de ascorbato, e interferências analíticas significativas em vários parâmetros bioquímicos séricos foram relatadas por estes autores.

Os resultados das determinações realizadas após a adição do ácido ascórbico in vitro mostraram que o ensaio para a quantificação de ácido úrico apresentou a maior interferência pelo ácido ascórbico, seguida pelos ensaios para triglicerídeos, colesterol total, glicose e bilirrubina (Figura 2 e Tabela 5). No entanto estes últimos sofreram interferência somente com as maiores doses de ácido ascórbico estudadas (10 e $40 \mathrm{mg} / \mathrm{dl}$ ). A creatinina, determinada pelo método de Jaffé modificado (picrato alcalino com duplo $\mathrm{pH}$ ), a uréia (uricase) e o fósforo (molibdênio) não sofreram interferência, nem mesmo na presença de $40 \mathrm{mg} / \mathrm{dl}$ de ácido ascórbico (resultados nãomostrados). Em geral, esses dados confirmaram os resultados de interferência observados após a ingestão de vitamina C (Tabelas 1 a 4) (27) e também por outros autores em estudos in vitro $(4,9,19,20,23,30,34)$. No entanto a interferência analítica observada para a reação da bilirrubina total após a adição do ácido ascórbico in vitro foi menor que aquela observada após a ingestão de vitamina $C$ por uma semana (Figura $3 \mathrm{~A}$ ). Esses resultados sugerem que o uso prolongado de ácido ascórbico interferiu no metabolismo da bilirrubina. Ensaios adicionais foram realizados determinando-se a bilirrubina total 2 e 4 horas após a ingestão de uma única dose de $4 \mathrm{~g}$ de vitamina C. Os resultados demonstraram que nesta situação o ácido ascórbico não provocou interferência negativa, confirmando, assim, a interferência in vivo. Até o momento, apenas o efeito interferente in vitro do ácido ascórbico na reação para a determinação da bilirrubina foi relatado $(9$,
30). Uma possível explicação para a interferência do ácido ascórbico no metabolismo da bilirrubina é o achado de Yamaguchi et al. (33), o qual mostra que a suplementação com ácido ascórbico diminuiu os níveis de RNA-m da hemeoxigenase-1, enzima limitante da biossíntese da bilirrubina.

Os resultados das determinações do ácido úrico após a suplementação vitamínica realizadas pelo método UV, o qual não se baseia no sistema oxidase/peroxidase e por isso não sofre interferência do ácido ascórbico, indicaram que as variações nos níveis de ácido úrico foram realmente devidas à interferência analítica do ácido ascórbico e não à biológica (Tabelas 1 e 2). Confirmação adicional foi conseguida observando-se que o grau de interferência nas determinações realizadas após a ingestão de vitamina C foi semelhante aqueles obtidos após a adição do ácido ascórbico in vitro (Figura 3B). No entanto, em relação à interferência do ácido ascórbico no metabolismo do ácido úrico, os estudos são controversos. Segundo Stein et al. (28) e Wilson e Liedtke (32), a administração crônica de vitamina $C$ resultou em substancial uricosúria e diminuição do ácido úrico sérico. Recentemente, levantaramse as hipóteses de que o ácido ascórbico pode ativar a formação de glicocorticóides e de que estes reduzam os níveis séricos de ácido úrico (29). Por outro lado, a suplementação com 4,8 ou $12 \mathrm{~g}$ de vitamina $C$ por dia não alterou os níveis séricos ou a excreção urinária de ácido úrico $(16,18,24)$.

De acordo com o nosso protocolo experimental, a dose de vitamina $C$ ingerida e o tempo de consumo não foram suficientes para provocar alterações significativas nos níveis de colesterol total (Tabela 1 e 2). A reação para triglicerídeos sofreu interferência analítica apenas 12 horas após a ingestão de $4 \mathrm{~g} / \mathrm{d}$ de vitamina C (Tabela 2). Os estudos in vitro confirmaram que a interferência nos ensaios desses analitos ocorreu apenas quando grandes concentrações de ácido ascórbico estavam presentes nas amostras (Tabela 5 e Figura 2). Outros autores, utilizando doses de vitamina $\mathrm{C}$ e períodos de consumo variados, têm demonstrado interferências analíticas e biológicas, porém de forma inconsistente. Por exemplo, Badrick e Campbell (2) observaram inibição analítica nos ensaios de colesterol total e triglicerídeos após a ingestão de $5 \mathrm{~g} / \mathrm{d}$ de vitamina C. A ingestão diária de $0,5 \mathrm{~g}$ de vitamina $\mathrm{C}$ por um período de um mês foi suficiente para acarretar significante redução nos níveis de colesterol total plasmático, porém não causou efeito nos triglicerídeos (3). No entanto a suplementação com 0,2 e $2 \mathrm{~g} / \mathrm{d}$ de vitamina $C$ por seis semanas (1) ou a 
ingestão de $4 \mathrm{~g} / \mathrm{d}$ de vitamina $C$ por quatro meses (16) não afetou os níveis dos lipídeos séricos.

Existem vários estudos demonstrando algumas medidas adotadas para eliminar a interferência provocada pelo ácido ascórbico quando presente em amostras biológicas. Atualmente, a enzima ascorbato oxidase é comumente utilizada para eliminar a interferência do ácido ascórbico na reação de oxidorredução. Comparando-se com outros tipos de tratamento para eliminar a interferência causada pelo ácido ascórbico, como cloreto férrico, nitrito de sódio, periodato de sódio, ácido bórico e íon férrico, somente a enzima ascorbato oxidase mostrou completa eficiência (11, $21,24)$. No entanto é interessante notar que os níveis de interferência observados nesse estudo para o ácido úrico com o reagente da BioSystems, que utiliza ascorbato oxidase em sua formulação, foram semelhantes aos demais reagentes de outras marcas comerciais (Figura 2). É possível que a concentração de enzima utilizada ( $\geq 5 \mathrm{U} / \mathrm{l}$ ) não seja suficiente para neutralizar o efeito negativo do ácido ascórbico. Fossati et al. (8) conseguiram efeito satisfatório utilizando concentrações superiores a $200 U / I$ de ascorbato oxidase. Kayamori et al. (12) relataram que o uso desta enzima tem várias desvantagens, tais como elevado custo, variação entre os lotes e baixa estabilidade, e sugeriram que seqüestradores de radicais livres podem ser mais eficientes à neutralização do ácido ascórbico em amostras clínicas. Com base em nossos resultados, sugerimos que o consumo de vitamina $C$ seja interrompido 48 a 72 horas antes da coleta de sangue para a realização dos exames quando doses $\geq 0,5 \mathrm{~g}$ forem ingeridas, ou que seja usado o método UV para o ácido úrico.

Com base na meia-vida do ácido ascórbico e na informação descrita por Fossati et al. (8), muitos laboratórios fabricantes de reagentes preconizam um tempo médio de 90 min para que ocorra a oxidação do ácido ascórbico presente nas amostras e os ensaios possam ser repetidos com segurança. Demonstramos, pelas sucessivas determinações realizadas após a adição do ácido às amostras de soro, que o tempo de repouso necessário foi dependente da quantidade de ácido ascórbico presente na amostra. Verificamos que um significativo nível de interferência persistiu por até 24 horas na determinação de ácido úrico na presença de $5 \mathrm{mg} / \mathrm{dl}$ de ácido ascórbico (Figura 4). $\mathrm{O}$ colesterol total, a glicose e os triglicerídeos também mostraram importantes níveis de interferência até 8 horas após a adição do ácido. Assim, os resultados mostraram que a interferência persistiu por um longo período de tempo, proporcional à concentração de ácido ascórbico presente na amostra, e sugerimos que o ensaio deva ser repetido somente após 48 ou 72 horas.

Esses resultados nos levaram a investigar a possível interferência do ácido deidroascórbico, primeiro produto de oxidação do ácido ascórbico, e a estabilidade do ácido ascórbico em amostras de soro. Verificou-se que o ácido deidroascórbico não interferiu nas reações de Trinder (resultados não-mostrados). No entanto, não podemos desconsiderar que outros subprodutos da oxidação do ácido ascórbico, que ainda apresentam potencial redutor, possam causar interferência negativa (13). Os resultados sugerem que o ácido ascórbico parece ser mais estável no soro do que em solução aquosa e, assim, ser a causa da interferência. Realmente, o ácido ascórbico no soro apresentou uma meia-vida de aproximadamente 15 horas, determinado por HPLC, e 48 horas juntamente com outros produtos de oxidação, determinados pelo método colorimétrico (Fig. 5), muito superior, portanto, à meiavida do ácido ascórbico em solução aquosa. Sevanian et al. (25) demonstraram que o ácido úrico em concentração fisiológica aumenta a estabilidade do ácido ascórbico no soro humano em aproximadamente cinco vezes. Isto sugere um importante papel fisiológico do ácido úrico na preservação do ácido ascórbico no sangue e em outros fluidos biológicos.

Em suma, os resultados desse trabalho demonstraram que a ingestão de ácido ascórbico interferiu de forma significativa nos ensaios laboratoriais para a determinação de parâmetros bioquímicos séricos, principalmente do ácido úrico pela reação de Trinder (interferência analítica) e da bilirrubina (interferência fisiológica), podendo, desta forma, modificar o diagnóstico clínico laboratorial. Portanto cabe a todos os profissionais de saúde envolvidos, como fabricantes de reagentes, médicos e analistas clínicos, a introdução de métodos para minimizar os efeitos interferentes do ácido ascórbico, como, por exemplo, a adição de componentes que inibam a ação do ácido ascórbico e a orientação aos pacientes para suspender a ingestão de vitamina $C$ alguns dias antes da realização dos exames.

\section{Agradecimentos}

Aos Laboratórios Labtest Diagnóstica, Bioclin, Celm, BioSystems e Biodiagnóstica pelo fornecimento dos kits de reagentes. À Universidade Federal de Santa Catarina pelo suporte financeiro (Funpesquisa). 


\section{Referências}

1. Aro, A . et al. No effect on serum lipids by moderate and high doses of vitamin $C$ in elderly subjects with low plasma ascorbic acid levels. Ann. N utr. M etabol., 32: 133-7, 1988.

2. Badrick, T. \& Campbell, B. Effects of intravenous infusion of ascorbate on clinical chemistry tests. Clin. Chem., 38(10): 2160, 1992.

3. Beser, E.The effects of short-term vitamin C on plasma BUN, uric acid, cholesterol and triglycerides levels. Acta M ed. Hung., 48: 73-8, 1991.

4. Bridgen, M. L. Unorthodox therapy and your cancer patient. Postgrad. M ed., 81:271-80, 1987.

5. Cameron, E.Protocol for use of vitamin $C$ in treatment of cancer. Med. Hypotheses, 36:190-4, 1991.

6. Cameron, E.; Pauling, L. \& Leibovitz, B.A scorbic acid and cancer : A review. Cancer Res., 39:663, 1979.

7. Carr, A.C \& \& Frei, B. Toward a new recommended dietary allowance for vitamin $\mathrm{C}$ based on antioxidant and health effects in humans. Am. J. Clin. N utr., 69: 1086-107, 1999.

8. Fossati, P.; Prencipe, L. \& Berti, G. Use of 3,5-dichloro2-hydroxybenzenesulfonic acid/4-aminophenazone chromogenic system in direct enzymic assay of uric acid in serum and urine. Clin. Chem., 26(2): 227-31, 1980.

9. Freemantle, J.; Freemantle, M.J. \& Badrick, T. A scorbate interferences in commom clinical assays performed on three analyzers. Clin. Chem., 40(6): 950-1, 1994.

10. Frei, B.; England, L. \& Ames, B.N . A scorbate is an outstanding antioxidant in human blood plasma. Proc. Natl. Acad. Sci. (EUA), 86: 6377-81, 1989.

11. Inamdar, K.V.; Raghavan, K.G \& \& 11.Pradhan, D.S. Five treatment procedures evalueted for the elimination of ascorbate interference in the enzymatic determination of urinary oxalate. Clin. Chem., 37(6): 864-8, 1991.

12. Kayamo ri,Y.; Katayama,Y. \& U rata,T. N onenzymatic elimination of ascorbic acid in clinical samples. Clin. Biochem., 33(1): 25-9, 2000.

13. Kimoto, E. et al. A nalysis of the transformation products of dehydro-L-ascorbic acid by ion-pairing high-performance liquid chromatography. Anal. Biochem., 214: 38-44, 1993.

14. M arcovina, S.M.; G aur,V.P. \& Albers, J.J. Biolo gical variability of cholesterol, triglyceride, low- and high-density lipoprotein cholesterol, lipoprotein (a), and apolipo proteins A-I and B. Clin. Chem., 40(4):574-8, 1994

15. McC ormick, D.B.\& Greene, H.L.Vitamins: ascorbic acid. In: Burtis, C .A.\&Ashwood,E.R.(eds.). Tietz Textbook of Clinical Chemistry. 2. ed. Filadélfia:W .B. Saunders, 1994. p. 1311-6.

16. Menne, I.V. et al. Ascorbic acid and blood lipid and uric acid levels of students. S. Afr. M ed. J., 49(54): 2225-8, 1975

17. Miller, S.M.Vitamins. In: Bishop, M.L.; D uben-Engelkirk, J.L. \& Fody, E.P. (eds.). Clinical Chemistry. Principles, Procedures, Correlations. 3. ed. Filadélfia: Lippincott, 1996. p.603-7.

18. Mitch,W .E. et al. Effect of large oral doses of ascorbic acid on uric acid excretion by normal subjects. Clin. Pharmacol., 29(3): 318-21, 1981.

19. Pedrazzi, A.H .P.; Rodrigues, E.R. \& Zanardo-Filho,A. A ção redutora da vitamina $C$ em bioquímica clínica. Rev. Bras.Anal. Clin., 30(1): 5-6, 1998
20. Pesce, M.A.\& Bodourian, S.H. Interference with the enzymic measurement of cholesterol in serum by use of five reagent kits. Clin. Chem., 23(4): 757-60, 1977.

21. Petrarulho, M. et al. Preventing ascorbate interference in ionchromatographic determinations of urinary oxalate: four methods compared. Clin. Chem., 36(9): 1642-5, 1990.

22. Podmore, I.D.et al. Vitamin C exhibits pro-oxidant properties. Nature, 392: 559, 1998.

23. Rodrigues, E.R. et al. A ção interferente do ácido ascórbico no doseamento da glicose sérica e urinária e do ácido úrico sérico in vitro. Rev. Bras.Anal. Clin., 29(4): 220-2, 1997.

24. Rolton, H.A. et al. A simple, rapid assay for plasma oxalate in uraemic patients using oxalate oxidase, which is free from vitamin C interference. Clin. Chim.Acta, 182(3): 247-54, 1989.

25. Sevanian,A ;,D avies, K.J. \& H ochstein, P.C onservation of vitamin C by uric acid in blood. Free Radic. Biol. M ed., 1(2):117-24 1985.

26. Siest, G. et al. D rug interference in clinical chemistry: studies on ascorbic acid. J. Clin. Chem. Clin. Biochem., 16(2): 103-10, 1978.

27. Silva, E.L. et al. Efeito interferente do ácido ascórbico nas determinações de parâmetros bio químicos séricos. Rev. Bras. Anal. Clin., 31(3): 111-5, 1999.

28.Stein, H .B.; H asan,A .\& Fox, I.H .A scorbic acid-induced uricosuria: a consequence of megavitamin therapy. Ann. Int. Med., 84: 385-8, 1976.

29. Sumbaev,V.V. \& lasinskaia, I.M. Effect of ascorbic acid on uric acid formation in men and animals. W MJ,69(2):116-20, 1997.

30.Vinet, B. \& Letellier, G.The in vitro effect of drugs on biochemical parameters determined by a SMAC system. Clin. Biochem., 10(1): 47-51, 1977.

31.W eber, J.A . \& van Zanten,A .P. Interferences in current methods for measurements of creatinine. Clin. Chem., 37(5): 695700, 1991.

32. W ilson, D.M. \& Liedtke, R.R. Modified enzyme-based colorimetric assay of urinary and plasma oxalate with improved sensitivity and no ascorbate interference: reference values and sample handling procedures. Clin Chem., 37(7): 1229-35, 1991.

33.Yamaguchi,T. et al. Bilirrubin oxidation provoked by endotoxin treatment is suppressed by feeding ascorbic acid in a rat mutant unable to synthesize ascorbic acid. Eur. J. Biochem., 245: 233-40, 1997.

34.Zoppi,F.\& Fenili, D.D rug interferences in reactions for detecting hydrogen peroxide by means of peroxidase. Clin. Chem., 26: $1229-30,1980$
Endereço para correspondência

Edson Luiz da Silva

Departamento de Análises Clínicas, CCS Universidade Federal de Santa Catarina

Campus Universitário - Trindade CEP 88.040-970 - Florianópolis-SC e-mail: edson@ccs.ufsc.br 